\author{
기계산업 작업자의 안전성 구축을 위한 작업복 기능배색 연구 1: \\ 상하의 명도 배색을 중심으로 \\ 박 혜 원 \\ 창원대학교 의류학과
}

\title{
The Functional Color Arrangements for Industrial Safety in Machinery Work Site 1: \\ Focusing on Lightness Value from Top and Bottom
}

\author{
Park Hyewon
}

Dept. of Clothing \& Textiles, Changwon National University

\begin{abstract}
This study researches functional arrangements for colors of work clothes - concentrating on the arrangements of lightness - for safety protection of workers at the job sites in the mechanical industry. To conduct such study, blue color (5PB) is selected for the CAD simulations on six arrangements of brightness based on two colors.

The brightness ranges are of 5PB color (between 3 7.5) which are measurable by Munsell Conversion, and arrangements on lightness consisting of one arrangement of high lightness-gap, two of medium lightness-gap, and three of low lightness-gap.

To analyze the data of color values after applying arrangements of lightness and to evaluate the levels of awareness regarding arrangements, the NCS colorimetric is being applied. Color palettes are based on the NCS notations, and then marked with color triangles.

After evaluation, the visibility proves to be high when the arrangements contain high lightness at the top and bottom, and the arrangements with higher lightness-gap show higher effects in safety.

Since this study tends to check factors of lightness, the other color factors were limited.
\end{abstract}

Corresponding author; Park Hyewon, Tel. +82-55-213-3494, Fax. +82-55-213-2724

E-mail: hwpark@changwon.ac.kr

This work was supported by National Research Foundation of Korea(NRF) grant funded by the Korea government(MSIP)(No. 2012R1A1B5003705). 
Therefore, in order to apply these results at the job sites, integrated applications of such results will be very useful for developing safe working clothes in the future.

Key words : color lightness value in work clothes(작업복 명도), functional color arrangement (기능배색), industrial safety(산업 안전), work clothes color(작업복 색)

\section{I. 서 론}

최근 산업현장의 안전에 관련된 연구는 매우 다양 화되어 인간공학적, 심리적, 건강과 위생, 산업시스 템 공학, 그리고 사회학적 접근이 시도되고 있다 (Carvalho, Santos, Gomes, Borges, \& Guerlain, 2008; Larson, Pousette, \& Torner, 2008; Parker, et al., 2003; Yi, Kim, Kim, \& Koo, 2012; Zohar, 2008). 이와 함께 의류학 분야에서도 산업현장에서 착용되는 작업복 연구가 활발히 진행되어 소재나 동 작 중심의 평가(Bae, Park, \& Park, 2010; Choi, Kim, \& Lee, 2004; G. Park, Park, Bae, \& Kim, 2011; G. Park, Park, \& Bae, 2012; Hong et al., 1996; H. Park \& Park, 2008a; H. Park \& Park, 2008b; Seongsook Kim \& Kim, 2008) 뿐 아니라, 작업환경과 작업자의 정서적 측면까지 포함한 실태 조사와 안전 작업복 디자인 개발연구 $(H$. Park, 2010a; H. Park, 2010b)도 이루어지고 있다. 의복 은 제 2 의 피부로 명명되며, 의복과 환경에 대한 연 구들이 지속적으로 이어져 온 결과로 볼 때, 작업복 은 작업자를 보호 할 수 있는 1차적 매개체임이 분 명하다. 산업현장의 안전을 위한 통합적 색채조절 영역에 작업복 색채를 포함시켜야 한다는 선행연구 (H. Park, 2010b)가 진행되었다. 이제는 실질적으로 작업복 색채의 구체적 기능을 관찰하고 이를 통제할 수 있는 기능배색의 가이드라인이 구체화 되어야 할 시점이다.

색채는 물리적 속성이 복잡하고 또한 정서적, 심 리적 속성에 따른 주관성을 가지고 있다. 산업현장 마다 서로 다른 환경색채와 작업조도가 있어서 획일 화된 작업복의 색으로는 안전성을 확보하기는 어렵 다. 그러나 인간의 시감체계에 작용하는 몇 가지 기 본 체계를 적용한다면 산업현장의 작업복 색채를 통
한 작업장의 안전성 확보에 도움이 될 수 있을 것이 다. 이는 색이란 물질적인 것 이상의 상징적 의미를 내포하기 때문이다. 즉 색이란 인간의 안구에 지각 되어 색료 빛의 물리적 수정의 결과이기도 하지만, 두뇌에 해석되는 결과(심리학적 과정)로서 수많은 자극의 복잡한 학습의 결과이기 때문이다(Roy, 2003).

그러나 산업현장의 근로자들이 착용하는 작업복은 패션의 색채와는 달리 미적인 요소는 제한적이고, 기능이 고려된 제한된 형태와 목적이 있다. 이러한 작업복의 특성은 단순하게 색채를 기능배색에 따라 적용할 수 있는 장점이 된다. 작업장의 환경과 조도 를 고려한 작업복 색채는 작업자를 빨리 그리고 명 확하게 시인시킬 수 있어서 안전성을 확보할 수 있 는 것이다. 즉, 색채는 인간의 필요를 충족시킬 수 있는 기능적 측면을 가지고 있기 때문에, 이를 적절 히 잘 활용 한다면 다양한 산업현장의 지원 요소로 활용될 수 있다는 점이 본 연구의 출발이다. 어두운 도로공사의 작업자에게 재귀반사띠를 부착한 조끼를 입히는 것과 같은 원리이다. 그러나 반사띠의 부착 은 오랜 시간, 동일 작업을 반복적으로 수행하는 기 계산업현장에서 다른 작업자의 눈을 지속적으로 자 극하게 하여 피로도를 높일 수 있다. 따라서 특수한 목적이외에는 사용하지 않고 대부분의 작업장에서는 일반적인 작업복만을 착용하고 있는 것이 현실이다.

최근 산업현장의 안전에 관해 다양한 학문 분야에 서 심도 있는 논의가 진행되고 있다. 이 중 산업안 전 의식 고취를 위해, 제반 여건의 개선보다는 표준 화, 인증화 시스템화, 교육화, 눈높이화 하는 것이 중요하며, 산업체에서의 안전한 작업환경을 구현하 기 위해서는 현장 안전 전반에 대한 요건이 시스템 되어 유기적인 관계를 이루어야 한다(Y. Yoon, 
박혜원 / 기계산업 작업자의 안전성 구축을 위한 작업복 기능배색 연구 1

2004)는 연구가 있다. 이를 위한 사례연구에서 동작 오류에 대한 안전사고에 대하여 인지, 행동, 판단, 감성 측면에 따른 분류가 수행되었고, 각각의 요소 에 대한 세부 대책을 세워 작업자들에게 적용을 한 후, 시행 전 후의 영향 평가가 이루어졌는데 '잊어 버림과 보지 못함' 순으로 작업자의 시각적 인지가 취약하다는 점이 대두되었다(Y. Yoon, 2004). 결국 작업자의 시각적 인지는 색채와 색채와의 관계 속에 서 이루어지는데, 생활환경에서 색채는 단독으로 사 용되는 일이 거의 없기 때문이다. 따라서 색채 간의 배색의 문제는 우리가 관심을 가져야 할 부분이다.

산업현장에서 작업자의 안전을 확보하는 1 차 매개 물은 착용하는 작업복이다. 작업자를 서로 알아보는 시각적 인지 즉, 식별의 기능(시인성, visibility) 확보 는 작업복의 색채를 통하여 조절될 수 있다. 실제로 색은 디자인, 조명, 환경 설계 등 여러 곳에서 이용 되고 있으나 색이 사람에게 불러일으키는 감각 및 정서 반응에 대한 체계적 분석과 이해를 위해서는 보다 많은 연구가 필요하다(Sangho Kim \& Park, 2004). 특히 위험성을 안고 있는 기계산업의 작업자 들 간의 소통과 정보를 전달하기 위한 색채의 연구 는 더욱 중요하다고 생각된다.

선행연구(H. Park, 2010a; H. Park, 2010b)에서 는 통합환경 계획을 위해 국내 기계업체의 작업복과 작업현장의 현장 조사가 수행되었고 통합환경 조화 와 안전성 구축을 위한 색채실태 사례에 대해 평가, 분석이 이루어진 바 있다. 우리나라의 제조업 가운 데 기계산업분야의 경우, 경상남도가 전국 생산액 대비 장비제조 1 위, 정밀기기 1 위, 자동차 3 위, 기 타 운송장비 1 위로 국내 기계 산업의 중심역할을 하 고 있다(G. Park et al., 2011).

따라서 본 연구의 목적은 경남에 위치한 국가산업 단지의 기계산업분야에 적용이 가능한 작업복의 기 능배색을 명도를 중심으로 연구 하는데 있다. 이러 한 시도는 그동안 시각적 판단에 의존하였던 작업복 색채 시인성 연구와 달리, 명도 배색의 정량적인 범 위를 제시함으로써 산업현장의 안전성을 구축하는데 도움이 되는 구체적 데이터를 확보하는데 그 의의가 있다.

이를 위해 선행연구조사에서 만족도가 높게 평가
된 색상을 중심으로 명도를 조절하고 조도범위를 설 정한 후, $\mathrm{CAD}$ 시뮬레이션으로 2 색의 명도배색을 수 행하고 그 결과를 전문가에 의해 평가 하고자 한다.

\section{II. 연구 방법 및 내용}

\section{1. 문헌 및 선행연구조사}

국내외 학술지를 통한 작업복과 색채 그리고 산업 안전에 관련된 선행연구를 살펴보고 산업안전보건원 과 노동부 자료를 조사하였다. 또한 색채이론에 관 련된 문헌과 연구 자료를 통해 배색과 시인성에 대 해 살펴보았다. 이를 통해 작업복 기능배색의 필요 성과 연구동향을 확인하였다.

\section{2. 색채 분석 및 명도 배색의 시뮬레이션}

기본 이미지 자극물은 선행연구(H. Park, 2013)의 사진을 선정하였으며 색차계(CR400)를 이용하여 작 업장 배경과 작업복의 색채값을 분석하였다. 선정된 사진의 작업장은 야외였으며 당일 조도는 2,400lux 이었다. 작업장 배경은 주변의 통, 철구조물 $\mathrm{A}, \mathrm{B}$, $\mathrm{C}$, 호스 등 기계작업장에서 흔히 볼 수 있는 환경이 었다. 색채값(HVC)을 분석하여 작업 현장의 색채적 현황(컬러 팔레트, NCS notation, NCS 색 삼각 형, 컬러 서클)을 확인하였다. 색채값은 분석하고자 하는 부분에서 임의의 세 곳의 색상을 색차계로 촬 영한 후, 세 곳의 평균값을 사용하였다.

시뮬레이션 실험을 위해 선정된 색상은 파랑(5PB) 색이며 선정 이유는 선행연구(H. Park \& Yang, 2012)에서 파랑색이 기계산업 현장의 적절한 색채 로 높은 만족도를 나타내었기 때문이다. 또한 파랑 색계열이 작업자에게 긴장감과 서로 다른 색상과의 조화로 주의를 환기시킬 수 있는 안전망(safety net) 구축에 적절하다고 지적한 선행연구의 결과(Yi et al., 2012)와도 일치하기에 파랑색을 본 연구에서 사 용하였다.

배색은 일반 작업복에 적용할 수 있도록 작업복 상하 의복의 주조색을 중심으로 하는 2 색 배색을 기 본으로 하였다. 명도 배색은 총 6 가지로 진행하였 
다. 명도차가 큰 배색(고명도 : 저명도), 명도차가 중간인 배색(고명도 : 중명도, 중명도 : 저명도), 그 리고 명도차가 적은 배색(고명도 : 고명도, 중명도 : 중명도, 저명도 : 저명도)이다. 각 배색을 상의와 하 의에 2 배색으로 시뮬레이션 하여 그 결과를 확인하 였다.

먼셀 색채 프로그램(Munsell conversion)에서 명 도값을 조절하여 색채를 얻었고, 이를 Texpro Design CAD 프로그램을 이용하여 작업장의 작업복 색상을 변경(3D Mapping)시켰다. 작업복 명도 배색 은 $5 \mathrm{~PB}$ 색상에서 먼셀 색채 프로그램으로 측정이 가능한 명도 범위(3 7.5)에서 진행하였다. 색채배색 적용을 마친 뒤 작업배경의 색채값과 작업복 명도 배색 변환 전후의 색채를 정리하여 각각의 색채 데 이터를 얻었다. 이를 색채표 및 NCS 색체계로 정리 하여 비교하였다.

\section{3. 평가 및 제안}

시율레이션 이미지 자극물 6개(명도차가 큰 배색 - 고명도 : 저명도, 명도차가 중간인 배색 - 고명도 : 중명도, 중명도 : 저명도, 명도차가 적은 배색 고명도 : 고명도, 중명도 : 중명도, 저명도 : 저명도) 에 대한 설문 평가를 수행하였다. 평가 항목은 작업 장의 안전과 관련된 질문으로 구성하였으며, 2013년 8월 19일부터 9월 11일까지 설문조사를 실시하였 다. 평가대상자는 의류학 전공자(석사, 박사학위자) 및 현장 안전전문가(안전팀 근무 5년차 이상)로 총 8명으로 구성하였다.

평가방법은 평가대상자에게 명도 배색 시율레이션 이미지 자극물을 보여주고, 5점 리커트 척도의 평가 지에 평가하도록 하여 평균값을 내었다. 결과를 통 해 안전성에 도움이 되는 명도배색 범위의 데이터를 확보하고 해석 후 연구의 제한점과 후속연구를 제안 하였다.

\section{III. 연구결과 및 고찰}

\section{1. 문헌 및 선행연구 조사}

1) 국내 산업안전과 기능배색

산업안전보건원의「재해조사보고서」에 따르면, 2011년 3월까지의 산업재해보상을 받은 사고 부상 자는 총 8,841 명이며 이를 분석한 결과 제조업이 $33.4 \%$, 건설업이 $24.0 \%$ 등이었다. 주요 발생 형태 는 전도, 전복이 $25.6 \%$, 충돌과 접촉에 의한 사고재 해가 $23.4 \%$, 협착이나 감김이 $17.7 \%$ 순이었고 주 요 기인물은 건축, 구조물, 표면의 문제가 $32.7 \%$, 설비, 기계가 $22.6 \%$ 였으며 주요 작업 공정은 저장, 운송, 교통, 보행지역이 $24.1 \%$, 토목, 건축, 플랜트 공사지역과 공정이 $22.6 \%$, 기계, 장비 제조지역이 $13.4 \%$ 순이었다.

작업 내용은 운반이나 운전작업이 $32.0 \%$, 물체의 가공과 취급작업이 $21.1 \%$, 기계 기구, 설비 설치, 보전작업이 $\quad 13.8 \%$ 등의 순서로 요약되었다 (Occupational Safety \& Health Research Institute [OSHRI], 2011). 이러한 재해 내용을 살펴보면 시 각적 부주의와 같은 사람의 인지적 요인의 부주의로 발생될 수 있는 물체와의 충돌, 사람과의 충돌 및 접촉, 상세정보 부족에 의한 충돌과 접촉의 가능성 이 상당히 있음을 알 수 있다. 작업 내용별 분석에 의하면 운반, 상하역 및 운전작업 중 재해를 입은 작업자의 수가 전체 사고 인원 8,841 명 중 2,828명 으로 $32.0 \%$ 를 차지하였고 물체의 가공과 취급작업, 기계 기구 설치, 보전작업, 물체의 연결, 조립, 설치 등이 $21.1 \%, 13.8 \%$ 순으로 나타나고 있다.

또한 제조업의 경우 금속가공제품 제조업 $15.9 \%$ 로 가장 높았고 다음으로는 기계 및 장비 제조업이 $13.5 \%$ 순으로 기계산업 분야의 재해 빈도가 높았 다. 사업장의 규모에 있어서는 5인 미만, 5-10인 미 만의 소형 사업장이 $32.2 \%, 17.4 \%$ 로 재해의 반을 차지하였다(OSHRI, 2011). 또한 개인보호장비 착용 대상자는 $6.6 \%$ 인데 반하여 비대상자(일반 작업복 착용 대상자)는 무려 $93.4 \%$ 의 대부분을 차지하여 (OSHRI, 2011) 산업재해의 대상자는 개인보호장비 착용대상자(극한 환경 작업자) 보다 일반 작업복을 착용하는 보통의 공장에서 일어나는 것으로 파악된다.

그리고 재해자의 평소 작업 중에 상해를 입는 경 
박혜원 / 기계산업 작업자의 안전성 구축을 위한 작업복 기능배색 연구 1

우가 93.3\%로 대부분이어서 일상적인 업무를 보는 생산 현장의 작업자에게 대부분 일어나고 있음을 알 수 있다. 이는 일상 작업복 착용자를 위한 산업안전 대책이 필요함을 의미 한다.

또한 고용노동부의 「2011년 산업재해 현황분석 보고서」의 직접원인별 분석에 의하면 제조업의 경 우 사망재해 총 286건 중 불안정한 상태 방치 121 건을 제외하고 복장보호구의 잘못 착용이 16 건, 감 독 및 연락불충분이 64건으로 작업복과 소통 부재로 인한 피해가 컸음을 알 수 있다(Ministry of Employment and Labor, 2012).

만케(Mahnke)는 그의 저서 「Color, Environment and Human Response(1996)」에서 시각적 인지에 포커스를 맞춘 서로 다른 색채의 체계는 유럽의 여 러 다른 산업공장에서 활용된다고 하면서, 사고를 감소시킬 수 있다고 지적하고 있다(Mahnke, 1998/2002).

워너와 피터젤(Werner \& Peterzell, 1990)은 산업현 장의 많은 사고들은 시각적 인지요소(perceptual factors)에 의해 발생되는데 특히 작업자의 연령이 50 세 이상인 경우 이러한 시인성에 대한 시력 약화로 발 생 빈도가 높다고 하며, 노화의 현상에 의해 시각정보 를 즉각적으로 얻기 쉽지 않다고 말한다.

K. 이시하라와 S. 이시하라(K. Ishihara, \& Ishihara, 2001)는 역시 중장년층을 위한 색채 배색을 실험과 컴 퓨터 시뮬레이션을 통해 제안하고 있다. 이러한 일련의 연구는 시각적 인지를 통해 사람들이 위험에 노출될지 모르는 현장에서 경계심을 갖게 하기 위하여 색채를 기능적으로 활용하는 예이다.

배색이란 어떤 목적을 위해 색과 색을 조합하여 새 로운 효과를 이루어 내는 것으로 단순히 여러 가지의 색을 배열하는 것이 아니라 단색으로는 쉽게 표현하기 어려운 이미지를 명확하게 전달할 수 있고 중요한 정 보를 효과적으로 강조 할 수 있는 것을 말한다. 예를 들어 포스터나 상업용 전시물의 경우 구성색의 색상을 대비시키거나 명암차를 크게 둠으로써 두드러진 인상 을 주어 주목을 끌기도 한다(H. Yoon, 2007).

따라서 본 연구에서 언급한 기능배색이란 색채의 기능을 고려한 목적에 적합한 배색을 의미한다.

결국 기능배색의 응용은 무관심이나 단조로움이
주의력을 약화시켜 생명과 신체에 위험을 초래할 수 도 있는 산업 현장에서는 합리적인 목적으로 쓰이는 것이다(Faber, 1995/2008). 산업현장에서는 색채의 사용과 활용이 그 어느 때보다 중요하게 되었으며, 기계적인 환경에서 장애물이나 위험물의 색채를 통 한 색인작업 즉, 색채분리는 주목되어야 할 부분에 주의를 끌기 위하여 색채를 선택적으로 사용하거나 긴장감을 표현하기 위한 표현의 기능으로 이용된다. 이런 기능은 안전을 위한 색채 기능을 수반하는 일 종의 부호화이다.

색인작업, 색채분리의 기능을 통해 작업장, 공장 등에서 작업자를 보호할 수 있으며, 관리감독관의 업무를 도울 수 있다. 따라서 기능배색을 통한 안전 효과란 활동에 지장을 초래하지 않으며 위험을 방지 하여 안전에 도움을 주는 색채효과를 말한다. 즉 색 채의 명시성과 주목성 등을 통하여 시인성을 확보하 는 것은 작업자를 보호하고 주의를 환기시키는 것이 근본이다. 주목성(attractiveness)은 색이나 빛에서 자극이 강하여 눈에 잘 띠는 성질을 말한다. 예를 들면 빨간색과 같은 난색계의 색상은 주목성이 강한 색이다. 한편, 명시성(clear vision)은 두 가지 색을 대비시켰을 때 멀리서 잘 보이는 성질을 말하며, 색 자체가 자극성이 강하여 눈에 잘 띠는 성질을 말한 다. 이에 대해 시인성(high visibility)은 색채의 특성 들을 활용하여 멀리서 눈에 잘 띠는 성질을 의미한 다고 볼 수 있다.

작업자의 안전을 위하여 작업자가 과도하게 긴장 을 풀지 않도록 하거나 위험요소를 없애기 위해서는 주목성과 명시성이 높은 색을 사용한 시인성 확보가 필요하다. 즉 작업장에서의 환경 색채는 작업자의 생리, 심리, 정신에 영향을 미치므로 작업자의 사고, 안전, 작업수행을 위한 조건으로 작용하게 된다. 따 라서 작업자가 착용하는 작업복은 산업공단의 작업 환경 색채계획에 있어 매우 중요한 문제가 되므로, 색채 기능을 고려한 작업복 연구로서 기능배색 연구 가 필요하다. 또한 이를 통해 작업복의 영역까지 확 장된 산업공단의 환경색채가 통합계획 되어야 할 것 이다.

2) 색채조화론에서의 명도 
명도(lightness)란 색의 밝고 어두운 정도를 말하 며, 색의 3속성 중 표면의 밝기에 관련된 양이라고 할 수 있다. 밝기(brightness)란 어느 영역이 발하고 있는 빛의 절대적인 양의 대소에 관련된 감각량이 고, 명도(lightness)란 같은 상태에서 조명된 백색면 의 밝기를 기준으로 판단되는 표면의 상대적인 밝기 를 의미한다. 따라서 두 용어는 구별하여 사용하여 야 한다. 즉, 조명의 세기를 높이면 밝기는 증대하 지만 명도는 조명의 강약에 관계없이 일정하다 $(H$. Yoon, 2008). 왜냐하면 명도를 판단할 때의 백색면 의 밝기도 조명의 강약에 따라 증가하거나 감소하기 때문이다.

먼셀의 색체계에서는 명도의 속성을 벨류(Value) 라는 용어로 사용하여 흰색을 10 , 검정을 0 으로 하 고 그 사이의 회색 단계를 10 등분하여 번호를 매긴 다. 한국산업규격(KS) A 0011 에서는 무채색의 수치 가 $10 \sim 8.5$ 까지의 영역을 '흰색', $8.5 \sim 2.5$ 사이 의 색을 '회색', $2.5 \sim 0$ 까지의 색을 '검정'이라고 한 다("Names of non - luminous object colours", 2010).

미국의 색채학자 저드(D. B. Judd, 1900 1972) 는 색채조화의 구성을 간단한 법칙에 의해 규정하는 것에는 한계가 있지만, 과학적으로 증명되지 않은 수많은 불완전한 기록과 부분적인 연구에서도 원칙 이 분명한 배색을 선택하기 위한 훌륭한 지침은 있 다며, 색채조화에 대한 선행연구를 종합하여 질서 (order)의 원리, 친근성(familiarity)의 원리, 유사성 (similarity)의 원리, 명료성(Unambiguity)의 원리를 제시한 바 있다(H. Yoon, 2008).
특히 명료성의 원리에서는 명도차가 어느 정도 커 야 색이 구별이 쉽고 애매함이 없어 조화롭다고 시 사하고 있다 그러나 실제 명료하지 않은 관계에서도 조화로울 수 있지만 포스터나 패키지 디자인에서와 같이 명료성이 중요한 배색은 많이 존재한다.

한편 문과 스펜서(P. Moon \& D. E Spencer, 미 국)의 색채조화론(Moon-Spencer's theory of color harmony)에서는 배색의 아름다움에 관한 면적비나 아름다움의 정도 등의 문제를 정량적으로 시도하였 다. 문과 스펜서에 의해 색채조화의 정량적 방법이 제시된 조화론은 3가지 논문 '고전적인 색채 조화론 의 기하학적 공식화(geometric for mulation of classical color harmony), 색채 조화의 면적(area in color harmony), 색채 조화에 적용되는 심미도 (aesthetic measure applied to color harmony)'에 서 볼 수 있는데, 여기서 색채 조화의 정량적 방법 을 제시하였다. 명쾌한 기하학적인 관계를 중시하여 조화의 종류를 동일 조화(identity)와 유사 조화 (similarity), 대비 조화(contrast)의 세 가지로 분류 하였으며, 또 모호한 관계의 배색은 부조화된다고 하였다("Moon \& Spencer's theory of color harmony", 2007). 부조화의 종류는 제 1 불명료의 부 조화(first ambiguity; 아주 유사한 색의 부조화), 제 2불명료의 부조화(second ambiguity; 약간 다른 색 의 부조화), 눈부심의 부조화(glare; 극단적인 반대 색의 부조화)로 분류하였다. 이를 먼셀 색체계의 3 속성인 색상차, 명도차, 채도차와의 관계로 표시한 것이 Table 1이다. 또한 조화배색은 쾌감을 주고, 부조화 배색은 불쾌감을 준다고 했다. 색의 조합에

Table 1. Relationship Between Moon-Spencer's Color Category and Munsell Color System

\begin{tabular}{c|c|c|c|c}
\hline \hline & Category & Difference of hue & Difference of value & Difference of chroma \\
\hline Harmony & Identity & $0 \sim 1$ j.n.d & $0 \sim 1$ j.n.d & $0 \sim 1$ j.n.d \\
\hline Inharmony & First Ambiguity & 1 j.n.d $\sim 7$ & 1 j.n.d $\sim 0.5$ & 1 1j.n.d $\sim 3$ \\
\hline Harmony & Similarity & $7 \sim 12$ & $0.5 \sim 1.5$ & $3 \sim 5$ \\
\hline Inharmony & Second Ambiguity & $12 \sim 28$ & $1.5 \sim 2.5$ & $5 \sim 7$ \\
\hline Harmony & Contrast & $28 \sim 50$ & $2.5 \sim 10$ & over 7 \\
\hline Inharmony & Glare & over 10 & \\
\hline \hline
\end{tabular}

* j.n.d.(just noticeable difference) 
는 쾌감과 불쾌감의 순서가 있으며 동시에 미적가치 가 있는데 이 미적가치가 높은 것이 조화라고 하였 다(H. Yoon, 2008).

\section{2. 작업 현장과 작업복 색채 분석}

기본 이미지 자극물은 경남 창원시에 위치한 기계 산업 분야 $\mathrm{D}$ 사의 현장 작업장을 디지털 카메라 (Cannon Powershot G6, 700만 화소)로 촬영한 것 이다. 색차계(CR400)를 이용하여 이미지 자극물의 작업장 배경과 작업복의 색채값을 분석하였다(Table 2, 3).

작업현장의 배경이 되는 통, 호스, 철구조물 $A, B$,
C 등의 색채값을 먼셀과 NCS 체계로 분석한 결과, 색상은 $\mathrm{R}, \mathrm{P}, \mathrm{Y}, \mathrm{PB}, \mathrm{GY}$ 계열로 분석되나 시각적 으로는 브라운, 베이지 색상으로 나타난다. 명도는 4.04 7.51 까지로 중명도에서 고명도에 해당하였 다. 채도는 구조물 $A$ 가 고채도(11.04), 구조울 B가 중채도(5.55)인 것을 제외하고는 모두 저채도의 범 위(0.49 2.44)였다.

작업복은 색상이 $\mathrm{YR}, \mathrm{PB}$ 이며, 명도는 상의가 5.77 , 하의가 2.13로 상의는 중명도이지만 하의는 저 명도 였다. 채도는 2.13, 2.66으로 모두 저채도 였다.

작업배경과 작업복의 명도 차이는 상의가 -1.73 $\sim+1.74$ 로 크지 않으나 하의의 경우는 $-1.94 \sim+$ 4.38로 비교적 큰 편이었다.

Table 2. Munsell Color Value of Industrial Environment \& Working Clothes

\begin{tabular}{|c|c|c|c|c|c|c|c|c|c|}
\hline \multirow{2}{*}{ Subject } & \multirow{2}{*}{\multicolumn{2}{|c|}{ Contents }} & \multicolumn{5}{|c|}{ Industrial environment } & \multicolumn{2}{|c|}{ Working clothes } \\
\hline & & & Barrel & Hose & $\begin{array}{c}\text { Steel } \\
\text { structure }\end{array}$ & $\begin{array}{c}\text { Steel } \\
\text { A structure }\end{array}$ & 3 Steel & Top & Bottom \\
\hline & & $\mathrm{H}$ & $2.02 R$ & $5.43 P$ & $3.76 Y$ & 4.90PB & $1.12 \mathrm{GY}$ & $5.87 Y R$ & 5.64PB \\
\hline & value & V & 6.02 & 4.41 & 8.53 & 4.04 & 7.51 & 5.77 & 2.13 \\
\hline & & C & 0.49 & 0.92 & 11.04 & 5.55 & 2.44 & 2.13 & 2.66 \\
\hline
\end{tabular}

Table 3. NCS Color Value of Industrial Environment \& Working Clothes

\begin{tabular}{c|c|c}
\hline Contents & Industrial environment & Working clothes \\
\hline Color palette & S4005-R20B / S7005-R50B / S1070-Y & S4005-Y20R / S7000-N \\
\hline NCS notation & $/$ S5030-R90B / S3010-G90Y & \\
NCS color triangle & \\
& & \\
NCS color circle & & \\
\hline
\end{tabular}


Table 4. Lightness Arrangement Simulation

\begin{tabular}{|c|c|c|c|c|c|c|}
\hline $\begin{array}{l}\text { Arrangement } \\
\text { Contents }\end{array}$ & $A$ & $B$ & C & D & E & $\mathrm{F}$ \\
\hline $\begin{array}{l}\text { Difference of } \\
\text { lightness }\end{array}$ & High level & \multicolumn{2}{|c|}{ Middle level } & \multicolumn{3}{|c|}{ Low level } \\
\hline $\begin{array}{l}\text { Simulation } \\
\text { result }\end{array}$ & & & & & $f\left(\begin{array}{ll}-1 \\
y^{2}\end{array}\right.$ & $f\left(\begin{array}{c}1 \\
y\end{array}\right.$ \\
\hline \multirow{2}{*}{$\begin{array}{l}\text { Lightness }(V) \\
\text { (top : bottom) }\end{array}$} & High : Low & High : Middle & Middle : Low & High : High & Middle : Middle & Low : Low \\
\hline & $7.5: 3$ & $7.5: 5$ & $5: 3$ & $7.5: 6.5$ & $6: 4.5$ & $4: 3$ \\
\hline
\end{tabular}

Table 5. The Before \& After Changes of NCS Variations for Working Clothes

\begin{tabular}{|c|c|c|c|c|c|c|c|}
\hline & \multirow{2}{*}{ Before } & \multicolumn{6}{|c|}{ Arrangement } \\
\hline & & $A$ & B & C & $D$ & $E$ & $\mathrm{~F}$ \\
\hline \multicolumn{8}{|l|}{$\begin{array}{c}\text { Color } \\
\text { palette }\end{array}$} \\
\hline $\begin{array}{c}\text { NCS } \\
\text { notation }\end{array}$ & $\begin{array}{c}S 4005-Y 20 R \\
/ S 7000-N\end{array}$ & $\begin{array}{l}\text { S2040-R90B } \\
/ \text { S5040-R90B }\end{array}$ & $\begin{array}{l}\text { S2040-R90B } \\
\text { / S3050-R90B }\end{array}$ & $\begin{array}{l}\text { S3050-R90B } \\
\text { / S5040-R90B }\end{array}$ & $\begin{array}{l}\text { S2040-R90B } \\
/ \text { S2050-R90B }\end{array}$ & $\begin{array}{l}\text { S2050-R90B } \\
/ \text { S3050-R90B }\end{array}$ & $\begin{array}{l}\text { S4050-R90E } \\
/ \text { S5040-R90 }\end{array}$ \\
\hline $\begin{array}{c}\text { Color } \\
\text { triangle }\end{array}$ & $\sum_{0=\infty}^{\infty}$ & $=$ & $\sum_{s=\infty}^{\infty}$ & $=\sum_{s}^{\infty}$ & $\sum_{-\infty=\infty}^{\infty}>0$ & $\underbrace{w}_{s=\infty}$ & s: \\
\hline $\begin{array}{l}\text { Color } \\
\text { circle }\end{array}$ & $\frac{5}{3}$ & & & & R & & \\
\hline
\end{tabular}

\section{3. 명도 배색 시뮬레이션}

명도 배색은 2색 배색을 기본으로 하였다. 이는 작업복의 형태적 특성상 상하의 투피스로 구성되며 패션의복과 달리 별다른 배색을 하지 않기 때문이 다. 5PB색상에서 Munsell Conversion으로 측정 가 능한 명도 범위(3 7.5)에서 총 6가지로 진행하였다. 명도차가 큰 배색은 <고명도(7.5) : 저명도(3)>의
$\mathrm{A}$ 배색, 명도차가 중간인 배색은 <고명도(7.5) : 중 명도(5)>, <중명도(5) : 저명도(3)>의 B배색과 C배 색, 명도차가 적은 배색은 <고명도 (7.5): 고명도 (6.5)>, 〈중명도(6) : 중명도(4.5)>, 〈저명도(4) : 저 명도(3)>의 D, E, F 배색이었다.

각 배색은 측정치의 차이 뿐 아니라 육안으로도 2 색 배색이 파악되도록 하기 위해 해당 명도 범위에 서 최대 차이의 값을 선택하여 배색하였다.

자극물로 선정한 작업복 이미지는 Texpro Design 
CAD 프로그램을 이용하여 시율레이션(3D Mapping) 하였다(Table 4).

명도 배색을 시율레이션 한 총 6 가지 결과를 배색 에 대한 지각 정도를 살펴보고자 NCS 색체계를 적 용하여 살펴보았다. 배색 A부터 F까지의 배색별 컬 러 팔레트를 나열하고, 'NCS 컬러스캔 2.0'을 이용 하여 각 컬러에 대한 색채값을 측정하였다. 이를 NCS 표기법에 따라 뉘앙스(Nuance)와 색상(Hue)순 으로 표기하고, 색삼각형에 나타내었다.

각 배색별 명도차이를 색삼각형에 옮겨 놓음으로 써 동일색상에 대한 6 가지 명도 배색이 적절한 수준 에서 고루 분포되었으며 각 배색별 명도차이를 한눈 에 확인 할 수 있어, 명도배색 평가 대상으로 적절 히 시율레이션 되었음을 알 수 있었다(Table 5).

\section{4. 평가}

작업복 명도 배색 $A \sim F$ 에 대하여 해당 기계산업 작업장의 안전성에 관한 적절성에 대한 평가를 수행 하였다. 총 5 가지 항목으로 평가지를 구성하였고 평 가항목은 선행연구에서 검증된 시인성과 작업장환경 의 적합여부에 대한 설문이었다. 평가자는 전문가 집단으로 의류학 전공자 3 명(석사, 박사학위자)과
현장전문가 5 명(안전팀 근무 5년차 이상)으로 구성 하였다. 명도 배색 시율레이션 결과물(자극물)을 보 여주고, 전혀 아니다(1점), 아니다(2점), 보통이다(3 점), 그렇다(4점), 매우 그렇다(5점)의 5점 리커트 척도로 평가하게 하여 평균값을 구하였다(Table 6).

시인성(눈에 잘 뜨임, 배경과 구별이 잘 됨)에 관 한 2가지 문항에 대한 평가 결과 '작업환경에서 작 업복이 눈에 잘 띄어 안전사고 감소에 도움이 될 것 이다'는 문항에서는 $A(3.63)>B, D(3.25)$ 의 순으로 긍정적인 답변이 나왔고, '작업환경과 작업자의 구 별이 잘되어 안전사고 감소에 도움이 될 것이다'는 문항에서는 $A(3.63)>D(3.25)>B(3.13)$ 의 순으로 긍 정적인 답변이 나왔다. $E$ (중명도 : 중명도), $F$ (저명 도 : 저명도)가 낮은 평가가 나온 것은 두 배색 간 의 명도차이가 적기 때문인 이유와 명도차이가 적더 라도 고명도 끼리의 배색인 $\mathrm{D}$ 가 3.25 의 평가가 나 온 것으로 볼 때 $\mathrm{A}, \mathrm{B}, \mathrm{D}$ 와 같이 고명도가 포함된 배색이 만족도가 높음을 알 수 있었다. 그 중 $\mathrm{A}$ 와 같이 고명도가 포함되며 저명도와 배색하여 명도차 를 크게 한 배색(고명도 : 저명도)에서 가장 좋은 평 가가 나와 기계산업현장의 작업복으로서 효과가 큰 것으로 파악되었다.

Table 6. Evaluation Results Following Changes of Color Arrangements for Working Clothes

\begin{tabular}{l|c|c|c|c|c|c}
\hline \hline \multicolumn{1}{|c|}{ Arrangement of lightness } & $\begin{array}{c}\mathrm{A} \\
(\mathrm{H}: \mathrm{L})\end{array}$ & $\begin{array}{c}\mathrm{B} \\
(\mathrm{H}: \mathrm{M})\end{array}$ & $\begin{array}{c}\mathrm{C} \\
(\mathrm{M}: \mathrm{L})\end{array}$ & $\begin{array}{c}\mathrm{D} \\
(\mathrm{H}: \mathrm{H})\end{array}$ & $\begin{array}{c}\mathrm{E} \\
(\mathrm{M}: \mathrm{M})\end{array}$ & $\begin{array}{c}F \\
(\mathrm{~L}: \mathrm{L})\end{array}$ \\
\hline $\begin{array}{l}\text { Questions } \\
\text { reduce safety accident. }\end{array}$ & 3.63 & 3.25 & 2.75 & 3.25 & 2.50 & 2.50 \\
\hline $\begin{array}{l}\text { Since workers are visible at site, safety accidents } \\
\text { will be reduced. }\end{array}$ & 3.63 & 3.13 & 2.75 & 3.25 & 2.63 & 2.63 \\
\hline $\begin{array}{l}\text { The arrangement (brightness arrangement) of } \\
\text { work clothes is proper and harmonious. }\end{array}$ & 2.75 & 2.50 & 3.13 & 3.13 & 2.88 & 2.88 \\
\hline $\begin{array}{l}\text { I consider this color arrangement plan provides } \\
\text { proper work clothes for job environment. }\end{array}$ & 3.13 & 2.75 & 2.75 & 3.00 & 2.88 & 2.88 \\
\hline $\begin{array}{l}\text { This will help site manager to manage safety of } \\
\text { workers. }\end{array}$ & 3.13 & 3.13 & 2.88 & 3.50 & 3.00 & 3.00 \\
\hline \hline
\end{tabular}


'작업복의 배색이 적절히 잘 이루어져 조화롭다' 는 문항에 대한 평가에서는 $\mathrm{C}$ 와 $\mathrm{D}$ 가 3.13 으로 조금 높게 평가되었고, '작업 환경에 적절한 작업복의 색 채계획이라 생각한다' 는 문항에서는 $A(3.13)$ $>\mathrm{D}(3.00)$ 의 순으로 긍정적인 답변을 얻을 수 있었 다. 그러나 다른 배색과 큰 차이를 보이지 않은 점 은 명도 배색만으로는 조화성에 관한 충분한 답변을 얻기가 어렵다는 것을 나타낸다고 볼 수 있다.

'현장관리측면에서 작업자의 안전관리에 도움이 될 것이다'는 문항에서는 $\mathrm{D}(3.50)>\mathrm{A}, \mathrm{B}$ (3.13)의 순으 로 긍정적인 결과를 확인 할 수 있었다. 이 결과는 앞에서 언급한 고명도가 포함된 배색에서 시인성이 높게 나타났던 점과 관련이 있는 결과라고 판단된 다.

따라서 평가 결과를 종합해 볼 때, 명도 조절에 의한 안전성 구축에 유리한 작업복의 배색에는 고명 도의 배색이 요구됨을 알 수 있다. 그러나 매우 높 은 점수가 도출되지 않은 점은 다른 색채적 요소를 제한하였기 때문이라고 판단된다.

\section{IV. 결 론}

본 연구는 산업현장 작업자의 안전성 구축을 위한 작업복 기능배색에 관한 연구로 기계산업 현장에서 작업복의 2색 명도 배색을 통하여 안전성에 영향을 주는 명도 배색의 정량적 범위를 알아보는데 그 목 적이 있었다.

이를 위해 산업안전과 색채 활용에 대한 문헌연구 를 수행하였다. 우리나라 산업현장 재해의 경우 제 조업이 $33.4 \%$ 로 가장 높은 재해발생 분야였으며, 재해의 내용은 시각적 부주의와 인지적 요인의 부주 의로 발생하는 빈도가 높았다. 제조업 중 특히, 기 계 장비 제조업의 재해 빈도가 매우 높게 나와 기계 산업 분야 현장의 작업복을 통한 시각적 인지를 높 여줄 필요가 있다.

그러나 개인장비 착용대상자는 전체 제조업 작업 자의 $6.6 \%$ 인 반면, 비대상(일반 작업복 착용 대상 자) 작업자는 $93.4 \%$ 로 대부분을 차지하고 있었다. 또한 일상적인 작업 중에 재해가 일어나는 것으로
볼 때 일반 작업복의 안전 대책이 절실함을 알 수 있었다. 그리고 작업자의 연령도 점차 고령화되면서 시각정보의 인지 방법의 개선이 요구되고 있다.

작업복을 통한 안전대책의 가장 쉬운 방법은 색채 를 활용하는 것이며 작업복의 단순한 구조에 적용될 수 있는 2 색 배색을 검토할 필요가 있다. 색채는 많 은 요인의 통합적 작용에 의해 사람의 뇌에 인지를 주고 있어, 색채의 각 요인 중 안전과 관련시킬 수 있는 항목의 데이터가 필요하다.

이러한 기계산업 현장의 작업복의 시인성 확보를 위해 기본 배색인 명도배색의 실험을 수행하였다. 그 결과 작업복은 고명도의 배색이 적용되어야 한다 는 것을 확인 할 수 있었다. 특히 $7.5: 3$ 의 <고명 도 : 저명도>로 상하의 명도차를 4정도로 했을 때 그 효과가 가장 높게 나타났다. 즉 작업복 상하의 명도차를 크게 하는 것이 시인성을 높이는데 도움이 되며, 이를 통해 작업자의 안전성을 확보할 수 있을 것으로 기대된다. 명도차이가 적을 경우에는 상하의 모두 고명도로 적용하는 <고명도 : 고명도> 배색이 고려되어야 할 것이다. 그러나 국내 작업장의 작업 복들은 오염방지를 위해 저명도 일색인 것은 매우 유감인 상황으로 개선이 요구되어야 한다.

의복의 색이란 것은 명도만으로 이루어지지 않으 며 색상, 채도가 고려된 톤의 개념으로 접근해야 통 합적인 이미지를 형성하는데 유용하다. 본 연구는 다른 요인들은 통제함으로써 명도의 순수한 요인을 파악하고자 하는 의도로 진행되어 실제 현장에서 본 연구의 결과만을 적용하는 데는 무리가 있다.

따라서 채도를 중심으로 하는, 톤을 중심으로 하 는 후속 연구의 결과를 모두 통합하여 정량적 데이 터를 확보한다면 산업현장에 적용 가능한 색채 가이 드라인을 제안할 수 있을 것이라 기대된다.

\section{References}

Bae, H., Park, H., \& Park, G. (2010). The analysis on the work environment and working clothes wearing conditions of shipyard painters. Journal of the Korean Society of 
Clothing and Textiles, 34(3), 518-528.

Carvalho, P., Santos, I., Gomes, J., Borges, M., \& Guerlain, S. (2008). Human factors approach for evaluation and redesign of human-system interfaces of a nuclear power plant simulator. Displays, 29, 273-284.

Choi, J., Kim, S., \& Lee, J. (2004). A survey on the actual condition of wearing disposable coveralls of railroad rolling stock maintenance workers. Journal of the Korean Society of Clothing and Textiles, 28(8), 1165-1174.

Faber, B. (2008). Color \& human response (J. Kim, Trans.). Seoul: Sigongsa. (Original work published 1995).

Hong, K., Park, K., Kwon, H., Song, Y., Oh, S., \& Jeung, Y. (1996). Functional design process of coveralls for the improvement of mobility. Journal of the Korean Society of Clothing and Textiles, 20(2), 311-322.

Ishihara, K., \& Ishihara, S. (2001). Age-related decline in color perception and difficulties with daily activities-measurement, questionnaire, optical and computer-graphics simulation studies. International Journal of Industrial Ergonomics, 28, 153-163.

Kim, S. [Seongsuk], \& Kim, H. (2008). The evaluation of functionality with material-improved working uniform of construction field. Journal of the Korean Society of Clothing Industry, 10(2), 228-235.

Kim, S. [Sangho], \& Park, K. (2004). A study on color associations of the Korean for color coding of process control information. Journal of Korea Safety Management \& Science, 6(1), 187-199.

Larson, S., \& Pousette, A., Torner, M. (2008). Psychological climate and safety in the construction industry - mediated influence on safety behavior. Safety Science, 46, 405-412.

Mahnke, F. (2002). Color, environmental and human response (S. Choi, \& M. Lee, Trans.). Seoul: Gookje. (Original work published 1998).

Ministry of Employment and Labor. (2012). 2011 Analysis on the industrial accident. Sejong: Ministry of Employment and Labor.

Moon \& Spencer's theory of color harmony. (2007). Retrieved June 4, 2013. from http://terms. naver.com/entry. nhn?docld=269819 \&cid=1389\&categoryld=1389

Names of non-luminous object colours. (2010). Retrieved March 25, 2013. from http://www.standard.go.kr/CODE02/USER/0B/0 3/SerKS_View.asp\#

Occupational Safety \& Health Research Institute. (2011). 2010 Investigation of the industrial accident. Incheon: Occupational Safety \& Health Research Institute.

Parker, C., Baltes, B., Young, S., Huff, J., Altmann, R.,...Roberts, J. (2003). Relationships between psychological climate perceptions work outcomes: A meta analytic review. Jornal of Organizational Behaviour, 24, 389-416.

Park, G., Park, H., \& Bae, H. (2012). The classification of manufcturing work processes to develop functional work clothes: With a reference to the automobile, machine and shipbuilding industries. Journal of Fashion Business, 16(6), 21-35.

Park, G., Park, H., Bae, H., \& Kim, J. (2011). The analysis on work clothes clothing comfort and wearer mobility of welding and grinding workers in the machine and shipbuilding industries. Journal of Fashion Business, 15(2), 145-159.

Park, H. (2010a). Development and color evaluation of working clothes designd for integrated environment color planning in machinery industry sites. Journal of Fashion Business, 14(6), 53-69.

Park, H. (2010b). Case study color analysis of 
work clothes and industrial factories for coordinating environment planning: Focus on shipbuilding companies. Journal of the Korean Society of Clothing and Textiles, 34(3), $540-552$.

Park, H. (2013). The color arrangement of working clothes for visibility in machine industrial work site. Journal of Fashion Business, 17(3), 1-14.

Park, H., \& Park, G. (2008a). The distribution condition and clothing construction factors of the working clothes. Journal of Fashion Business, 12(3), 116-135.

Park, H., \& Park, G. (2008b). The actual wearing condition and preference of the working uniform design in the Industrial complex. Journal of Fashion Business, 12(2), 134-152.

Park, H., \& Yang, J. (2012). Color arrangement evaluation on working clothes for safety and integrated environment harmony in machinery industry fields. Journal of Fashion Business, 16(5), 207-219.

Roy, S. (2003). Principles of color technology (M. Cho, C. Kim, B. Kang, \& D. Kim, Trans.). Seoul: Sigmapress. (Original work published 2000).
Werner, J., \& Peterzell, D. (1990). Light, vision, and aging. Optometry and Vision Science, 67(3), 214-229.

Yi, J., Kim, Y., Kim, K., \& Koo, B. (2012). A suggested color scheme for reducing perseption-related accidents on construction work sites. Accident Analysis and Prevention, 48, 185-192.

Yoon, H. (2007). 색채심리 마케팅과 배색이론, [Color psychology marketing and color arrangement theory]. Seoul: Kukje.

Yoon, H. (2008). 색채지각론과 체계론, [Color perception theory and system theory]. Seoul: Kukje.

Yoon, Y. (2004). A study for human - error prevention of chemical plant safety accident. Journal of the Korea Safety Management and Science, 6(2), 1-9.

Zohar, D. (2008). Safety climate and beyond: a multi-level and multi-climate frame-work. Safety Science, 46, 376-387.

접수일(2013년 8월 17일)

수정일(2013년 9월 27일)

게재확정일(2013년 10월 4일) 